\title{
Effect of Selective Behavioral Therapy on Stress Urinary Incontinence and Self-esteem
} among Institutionalized Elderly Women

\author{
Rakaia Fathi Mohammed ${ }^{1}$, Sahar Hamza Taha ${ }^{2}$, Nermeen Mahmoud Abd-Elaziz ${ }^{3}$ \& El-Zahraa Abd-Elaziz Omar \\ 1. Lecturer of Geriatric Nursing, Faculty of Nursing, Minia University, Egypt. \\ 2. Lecturer of Medical-Surgical Nursing, Faculty of Nursing, Minia University, Egypt. \\ 3. Assistant Professor of Gerontological Nursing, Faculty of Nursing, Assuit University, Egypt. \\ 4. Lecturer of psychiatric Nursing, Faculty of Nursing, Minia University, Egypt.
}

\begin{abstract}
:
Stress urinary incontinence is an ignored health problem among elderly women. Aim: To evaluate the effect of selective behavioral therapy on stress urinary incontinence and self-esteem among institutionalized elderly women. A quasi-experimental research Design was utilized on a purposive Sample of 50 elderly women residing in three geriatric homes at Minia Governorate, Egypt. Tools: A Structured questionnaire sheet and three scales (Body Mass Index, Revised Urinary Incontinence, and Rosenberg Self-esteem Scales) were utilized. Results: The mean value of stress urinary incontinence severity declined to $(4.30+3.38)$ after 12 weeks of behavioral training sessions compared with $(8.20+5.21)$ before, besides, the mean score of self-esteem among the studied sample was elevated to $(15.48 \pm 5.75)$ at posttest with highly statistically significant differences between pre and posttests $(\mathrm{p}=.000)$. A negative correlation was found between the severity of stress urinary incontinence and self-esteem. Conclusion: The application of selective behavioral therapy included (Kegel exercise and toilet training) was effective in reducing the severity of SUI and consequently, elevation of self-esteem among institutionalized elderly women. Recommendations: Behavioral training sessions are recommended to be offered regularly for geriatric residents to improve their self-esteem by controlling stress urinary incontinence.
\end{abstract}

\section{Keywords: Behavioral therapy-Elderly-Institutionalized-Self-esteem \& Stress urinary incontinence.}

\section{Introduction}

The first frequent type of urinary incontinence among elderly women is stress urinary incontinence (SUI) which is known as a geriatric syndrome and is associated with profound adverse effects on body image, self-esteem, and the overall quality of life for them (Gümüsssoy et al., 2019). Women are at greater risk for SUI three times than men, because of anatomical, social, and cultural aspects (International Continence Society, 2018).

Globally, the occurrence of SUI among residents in geriatric homes ranges from 35 to $72 \%$. It is significantly greater than its prevalence among those living in the community. Likewise, the risk of geriatric home placement is considerably increases with the presence of this problem because it triggers the caregivers' burden and stress (Kramer et al., 2020).

International Continence Society (2018) described SUI as "the complaint of involuntary loss of urine that occurs during physical movement, exertion or activity (for example, coughing, sneezing, laughing, standing up or running, and heavy lifting).

It can be triggered by a variety of risk factors including; pregnancy, labor, menopause, overweight, heavy lifting, chronic cough or constipation, family history, lifestyle, and diabetes (Shaw and Wagg, 2017). Besides, a decreased bladder muscle strength and capacity as physiologic changes of aging, and the process of institutionalization itself (Aly et al., 2020). There are many problems can occur as a result of bladder control loss, like; frequent wetness, bad odor, discomfort, skin breakdown, bedsores, and urinary tract infection as physical consequences (Gümüşsoy et al., 2019). Furthermore, psychosocial alterations such as; embarrassment diminished self-esteem and negative self-worth (Jahromi et al., 2015), stigmatization (Elbana et al., 2018), depression, and social isolation are common to occur (Mohammed et al., 2018).

Behavioral interventions are a set of nonpharmacological actions aimed at managing urinary incontinence by modifying the patient's daily habits. Its selection depends on the type, severity, and consequences of incontinence (Ismail et al., 2019). It involves several approaches like; weight control, lifestyle modification, controlling of cough and constipation, but a combination of (Kegel exercise and bladder/toilet training) is currently recommended as the first-line behavioral therapy for managing SUI (Vaz et al., 2019). 
Since, they are noninvasive methods, not expensive; easy to be performed at home without the need for a hospital visit, most effective, and with no reported side effects, but their success highly depends on patients' motivation and compliance (Ismail et al., 2019).

Kegel exercise involves the repetitive contraction of the pelvic floor muscle, which builds pelvic strength and perineal support (Simpson, et al, 2019), while bladder training aimed at increasing the voiding interval and bladder control by toilet scheduling (Palmer, 2015). Doing both Kegel and bladder training helps strengthen the muscles and control urine leakage (Vaz et al., 2019). The results can be seen after eight to twelve weeks and more observable progress after three months (Mulvey, et al., 2017).

Management of urinary incontinence and its consequences is considered an important issue of nursing care, especially for those living in institutions. This can be achieved through providing the necessary education about the behavioral training therapy, enhancing motivation and compliance, the elevation of self-worth, and restoration of normal functional activities, so this research was conducted.

\section{Significance of the Study:}

Although stress UI is a common distressing problem and is considering one of the causative factors of institutionalization, it remains hidden and ignored problem in Upper Egypt. The typical magnitude of this problem is still not estimated related to the following reasons; there are limited studies that focus on the prevalence of SUI among residents in Upper Egypt, elderly women may consider this problem occurs as a normal consequence of aging, and/ or they feel embarrassed to seek health care.

Additionally, from our own clinical experience, we found that most residential elderly women at Minia City suffering from SUI without any previous designed educational intervention provided for them in order to solve this problem.

Aim of the study:

To evaluate the effect of selective behavioral therapy on stress urinary incontinence and self-esteem among institutionalized elderly women.

\section{Research hypothesis:}

Application of selective behavioral training therapy involved (Kegel exercise and bladder training) will decrease the severity of stress UI and elevate the level of self-esteem among institutionalized elderly women.

\section{Null hypothesis:}

Application of selective behavioral training therapy involved (Kegel exercise and bladder training) will not affect the severity of stress UI and self-esteem of institutionalized elderly women.

\section{Subjects \& Method:}

Research Design

A quasi-experimental research design (Pre-posttest) was utilized to fulfill the aim of this study.

Setting:

This study was carried out in three geriatric homes affiliated to Ministry of Social Solidarity in Minia City at Minia Governorate-Egypt, namely; (Dar AbdElrahman, Dar Omar Ebn El-Khatab, and Dar Elraee El-Saleh).

Subjects:

A purposeful sample of (50) elderly women were residence at the previous mentioned settings during the time of data collection and selected through a non-probability sampling technique according to the following inclusion criteria: Females of (60 years and older) who have at least one episode of involuntary urine loss/week), and without any recurrent treatment. Exclusion criteria: Cases with Any cognitive or psychological disorder that can affect communication and with any Pathological disorders as (spinal injury, stroke, neurogenic bladder, urinary tract infection, pelvic organ prolapse, and immobility) were excluded.

Sample size:

The sample size was calculated by using EP/Info website

(https://www.surveysystem.com/sscalc.htm) based on the following parameters; confidence interval: $95 \%$, population size (total number of residents in the three selected geriatric homes was (166) according to the last residential census, 2019, acceptable error: $5 \%$, then the required sample size was estimated to be 50 participants.

\section{Study Duration:}

The data was collected over a period of 7 months starting from October 2019 to the end of April 2020.

Tools of data collection:

Three tools were utilized for collecting the necessary data:

The first tool: A Structured interview questionnaire sheet was developed by the researchers based on relevant literature (Roig et al., 2016, Fouad and Hafez, 2017\& Mohammed et al., 2018), then translated into simple Arabic language in the form of close and open-ended questions filled by the researchers and covered 2 parts:

Part I: Demographic data: Included; age, marital status, education, job before retirement, and source of income.

Part II: Medical Profile: History of chronic diseases, weight, height, and then body mass index was calculated (WHO, 2006), obstetric/gynecological history, incontinence history involved; duration, 
frequency, and amount of stress UI episodes, medications, and mobility level).

The second tool: Revised Urinary Incontinence Scale (RUIS) developed by (Sandvic et al., 2000). It is a five-item questionnaire used to assess the severity of stress UI leakage. Participants respond to (RUIS) questions by selecting one particular response option from the set of standard response options for each question. These response options were scored by using the numbers presented in brackets to the right of each response option. After that, an incontinence severity index (ISI) score was calculated by multiplying the scores from questions 4 and 5 .

Question 4) how often does you experience urine leakage?

- Never (0)

- Less than once a month (1)

- A few times a month (2)

- A few times week (3)

- Every day and/or night (4)

Question 5) How much urine do you lose each time?

- None (0)

- Drops (1)

- Small splashes (2)

- More (3)

Incontinence Severity index $=$ (points for frequency $)$ $\mathbf{x}$ (points for amount)

The result of multiplications then was categorized as the following:

\begin{tabular}{|l|l|}
\hline \multicolumn{1}{|c|}{ ISI Score } & \multicolumn{1}{c|}{ Severity Levels } \\
\hline Zero & No incontinence \\
\hline $1-2$ & Slight \\
\hline $3-6$ & Moderate \\
\hline $8-9$ & Severe \\
\hline 12 & More severe \\
\hline
\end{tabular}

The third tool: Rosenberg Self-esteem Scale (RSES) developed by (Rosenberg, 1965) which is universally used for measuring self-esteem by assessing the positive and negative feelings about the self. This scale is a 10-item, Likert-type scale with items answered on a four-point scale (from strongly agree to strongly disagree). Five of the items have positively worded statements (items $1,2,4,6$, and 7) as the following (Strongly agree $=3$, Agree $=2$, Disagree $=1$, and strongly disagree $=0$ ). The remaining five items have negatively worded ones (items 3, 5, 8, 9, and 10) which are reversed in valence. The score of RSES is sorted from 0-30. When a person's Score is $(15-25)$, this indicates a normal level of self-esteem, while a score of less than 15 proposes low self-esteem.

The second and third tools were used twice (before and after the application of selective behavioral training therapy) to evaluate its effect on the severity of stress urinary incontinence and self-esteem respectively among the studied sample.

Educational brochure:

It was formulated by investigators in the simple Arabic language, revised by experts, and was rich in colorful figures. It contains; the definition of stress urinary incontinence, its causes, and an explanation of the behavioral training therapy involved (Kegel exercise and toilet training), focusing on its benefits, the technique of doing it, and the needed guidelines during its performance. It was given to each elderly woman after the end of the educational sessions.

Tools validity:

Five specialists (two in the field of geriatric nursing, one in the field of psychiatric nursing, and two urologists) were examined the tools to determine if the included items clearly and sufficiently cover the domain of the addressed content, and no changes were reported by them.

Tools reliability:

The internal consistency of the study scales was used to assess their reliability. Cronbach's coefficient alpha for the RUIS is 0.93, while Cronbach's alpha for Rosenberg's Self-Esteem Scale is 0.90, which indicating a high level of reliability.

\section{Pilot Study}

A pilot project was done to verify feasibility, objectivity, and applicability of the tools on $10 \%$ of the total sample and enrolled in the actual sample as a result of no modifications were required.

\section{Ethical Considerations}

Approval was obtained from the ethical committee in the Faculty of Nursing and from the directors of the selected geriatric homes at Minia city. Also, the permission of elderly women was obtained after the explanation of the study purpose. The confidentiality and anonymity of each participant were safeguarded, and the right of voluntary participation and the right of withdrawal at any time was protected. Besides, the maneuvers of the study didn't propose any dangerous effects for the participants.

\section{Study Procedure:}

The data was collected through the following phases.

Assessment phase:

After the necessary approvals were taken, researchers visited the selected settings alternatively through three days/weekly from 9:00 am to 2:00 pm. The first face-to-face interview was done with each participant to perform the initial assessment using the study tools to collect the following data (demographic data, medical profile, the severity of stress urinary incontinence and the level of self-esteem as a pretest). It took about 30 to 40 minutes depending on the educational level and the attention span. 


\section{Implementation Phase:}

- The implementation of the selective behavioral training therapy (Kegel exercise and toilet training) was established by dividing the Participants into 5 groups according to their settings, 3 sessions were organized for each group, and each session took about 30-45 minutes, using PowerPoint, printed panner, demonstration, and re-demonstration as teaching methods.

- At the end of each session, time was allowed for asking any questions, plus the Arabic brochure was offered for them. These training sessions were designed as the following:

The first Session: Covered an explanation of definition, causes, risk factors, and the negative consequences of stress UI, and the available methods of its treatment.

The second session: Included definition and benefits of Kegel exercise and how to perform it through the following steps:

a) Instruct each participant to empty the bladder before starting Kegel.

b) Get into a comfortable position. Start by lying down on the back, with arms at body sides and knees up and together.

c) Squeeze (contract) your pelvic floor muscles for 3-5 seconds, and relax for 3 to 5 seconds. Repeat the contract/relax cycle 10 times/ three times daily for 8 to 12 weeks.

d) Keeping other muscles relaxed (don't contract the abdominal, leg, or buttock muscles)

e) Extend the time. Gradually increase the length of contractions and relaxations to reach 10-second contractions and relaxations.

The third session: Focused on bladder training/toilet schedule which aims at raising the interval between voids, and increase the bladder capacity through the following steps:

a. Delayed urination: Each participant was instructed that if she has a desire to micturate, do not immediately go to toilet. Instead, try to be distracted for five to 15 minutes by relaxation techniques as breathe slowly and deeply and concentrate on your breathing until the urge goes). Continue to increase the amount of time until you're urinating every 2-3 hours.

b. Scheduled bathroom trips: Instruct respondent to go to the bathroom on a self-schedule with fixed interval whether she feels the urge or not. For example, start by going to the bathroom every hour, after that gradually raise the time interval between voiding until you find a schedule that is better for limiting incontinence episodes.

- All participants were instructed to adhere to this toilet schedule for at least (8 to 12 weeks) combined with the Kegel exercise to get successful results.
Evaluation phase:

- Follow-up was done for each participant (4 weeks, 6 weeks, and 8 weeks) after the application of the training sessions to ensure that all of them were adhered to Kegel exercise and toilet scheduling by visiting them in their geriatric settings or by calling them by telephone.

- After 12 weeks of the educational intervention, Post-test for the severity of stress urinary incontinence and self-esteem were done for participants using the second and third tools (revised urinary incontinence and Rosenberg Selfesteem Scales) respectively.

Statistical analysis of data:

After data collection, statistical analysis was done using the Statistical Package for Social Sciences (SPSS) version 20. Descriptive and analytical statistics were used, such as percentages, means, and standard deviations. Fisher Exact-test, correlation, and Paired T-test with a P-value was set at .05 to identify statistical significance difference between the results. 


\section{Results:}

Table (1): Frequency distribution of the studied sample according to personal characteristics (N=50).

\begin{tabular}{|c|c|c|}
\hline Personal Characteristics & $(\mathrm{N}=50)$ & $\%$ \\
\hline \multicolumn{3}{|l|}{ 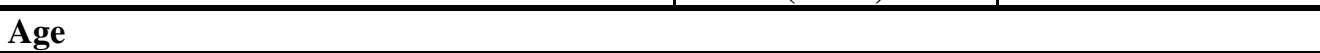 } \\
\hline - $60<65$ & 20 & 40 \\
\hline - $65<70$ & 22 & 44 \\
\hline - $\geq 70 \mathrm{yrs}$ & 8 & 16 \\
\hline \multicolumn{3}{|l|}{ Mean \pm SD $=(66.92 \pm 5.39)$} \\
\hline \multicolumn{3}{|l|}{ Marital status } \\
\hline - $\quad$ Single & 3 & 6 \\
\hline - $\quad$ Married & 9 & 18 \\
\hline - Divorced & 12 & 24 \\
\hline - Widow & 26 & 52 \\
\hline \multicolumn{3}{|l|}{ Education } \\
\hline - Illiterate & 9 & 18 \\
\hline - Basic/secondary & 29 & 58 \\
\hline - High education & 12 & 24 \\
\hline \multicolumn{3}{|l|}{ Place of residence (Institution) } \\
\hline - Dar Abd-El rahman & 18 & $36 \%$ \\
\hline - Dar Omar Ebn El-Khatab & 22 & $44 \%$ \\
\hline - Dar Elraee El-Saleh & 10 & $20 \%$ \\
\hline \multicolumn{3}{|l|}{ Reason of institutionalization\# } \\
\hline - No available caregiver & 45 & 86.5 \\
\hline - Living alone & 40 & 80 \\
\hline - Not having place to live & 12 & 24 \\
\hline - Own choice & 20 & 40 \\
\hline \multicolumn{3}{|l|}{ Job before institutionalization } \\
\hline - Heavy work & 20 & 40 \\
\hline - Light work & 15 & 30 \\
\hline - Not work (housewife) & 15 & 30 \\
\hline \multicolumn{3}{|l|}{ Income } \\
\hline - Sufficient & 14 & 28 \\
\hline - Insufficient & 36 & 72 \\
\hline \multicolumn{3}{|l|}{ Body Mass Index } \\
\hline - $\quad$ Normal & 6 & 12 \\
\hline - Underweight & 5 & 10 \\
\hline - Overweight & 15 & 30 \\
\hline - Obese & 24 & 48 \\
\hline $\begin{array}{c}\text { Family history of UI } \\
\text { - Yes }\end{array}$ & 34 & 68 \\
\hline
\end{tabular}


Table (2): Distribution of the Studied sample according to their medical/obstetric history (N=50).

\begin{tabular}{|c|c|c|}
\hline \multirow{2}{*}{ Medical history } & \multicolumn{2}{|c|}{ N0 $=50$} \\
\hline & Yes & $\%$ \\
\hline Presence of chronic disease \# & 43 & 86 \\
\hline - Diabetes & 25 & 50 \\
\hline - Hypertension & 29 & 58 \\
\hline - Cardiovascular & 15 & 30 \\
\hline - Arthritis & 17 & 34 \\
\hline - Hearing deficits & 5 & 10 \\
\hline - Liver disease & 6 & 12 \\
\hline - Visual deficits & 8 & 16 \\
\hline - Chronic cough & 9 & 18 \\
\hline - Chronic constipation & 14 & 28 \\
\hline Mobility & No & $\%$ \\
\hline $\begin{array}{l}\text { - Mobile independently } \\
\text { - Walk with assistive devices }\end{array}$ & $\begin{array}{l}39 \\
11\end{array}$ & $\begin{array}{l}78 \\
22\end{array}$ \\
\hline Medication & No & $\%$ \\
\hline - No medication taken & 7 & 14 \\
\hline - 1-3 types of medication & 20 & 40 \\
\hline - More than three types & 23 & 46 \\
\hline \multicolumn{3}{|l|}{ Obstetric history } \\
\hline \multicolumn{3}{|l|}{ No. of pregnancies } \\
\hline - Infertility & 3 & 6 \\
\hline - Less than 4 times & 18 & 36 \\
\hline - $\geq 4$ times & 29 & 58 \\
\hline \multicolumn{3}{|l|}{ Method of delivery } \\
\hline - Infertility & 3 & 6 \\
\hline - Vaginal delivery & 37 & 74 \\
\hline - Caesarian section & 10 & 20 \\
\hline
\end{tabular}

\# More than one answer

Table (3): Distribution of the studied sample according to their history of stress urinary incontinence (SUI) $(\mathbf{N}=\mathbf{5 0})$.

\begin{tabular}{|c|c|c|}
\hline \multirow{2}{*}{ History of stress UI } & \multicolumn{2}{|c|}{$\mathbf{N 0}=\mathbf{5 0}$} \\
\hline & $\mathbf{N}$ & $\%$ \\
\hline \multicolumn{3}{|l|}{ Duration (onset) } \\
\hline $\begin{array}{l}\text { - Less than } 5 \text { years } \\
\text { - } \geq 5 \text { years }\end{array}$ & $\begin{array}{l}5 \\
45\end{array}$ & $\begin{array}{l}10 \\
90\end{array}$ \\
\hline \multicolumn{3}{|l|}{ Occurrence of SUI episodes \# } \\
\hline $\begin{array}{l}\text { - During coughing } \\
\text { - During sneezing } \\
\text { - During laughing } \\
\text { - Heavy lifting }\end{array}$ & $\begin{array}{l}50 \\
48 \\
43 \\
42\end{array}$ & $\begin{array}{l}100 \\
96 \\
86 \\
84\end{array}$ \\
\hline \multicolumn{3}{|l|}{ Frequency of SUI episodes } \\
\hline $\begin{array}{l}\text { - More than one episode/day } \\
\text { - More than one episode/week }\end{array}$ & $\begin{array}{l}42 \\
8 \\
\end{array}$ & $\begin{array}{l}84 \\
16 \\
\end{array}$ \\
\hline \multicolumn{3}{|l|}{ Amount } \\
\hline - Small amount & 12 & 24 \\
\hline - Moderate amount & 22 & 44 \\
\hline - $\quad$ Large amount & 16 & 32 \\
\hline
\end{tabular}




\begin{tabular}{|c|l|l|}
\hline \multicolumn{2}{|c|}{ History of stress UI } & \multicolumn{2}{|c|}{ N0=50 } \\
\cline { 2 - 4 } & \multicolumn{2}{|c|}{ N } \\
\hline Action taken \# & 35 & 70 \\
\hline$\bullet \quad$ Nothing due to shame & 12 & 24 \\
\hline$\bullet \quad$ Using protective pads & 15 & 30 \\
\hline$\bullet \quad$ Limited fluid/caffeinated beverages & 3 & 6 \\
\hline Ask for medical advice & & 44 \\
\hline Adverse consequences of SUI \# & 22 & 70 \\
\hline$\bullet \quad$ Skin problems (rashes, irritation & 35 & 64 \\
\hline$\bullet \quad$ Loor hygiene & 32 & 56 \\
\hline$\bullet \quad$ Limiting social activities & 28 & 92 \\
\hline
\end{tabular}

\# More than one answer

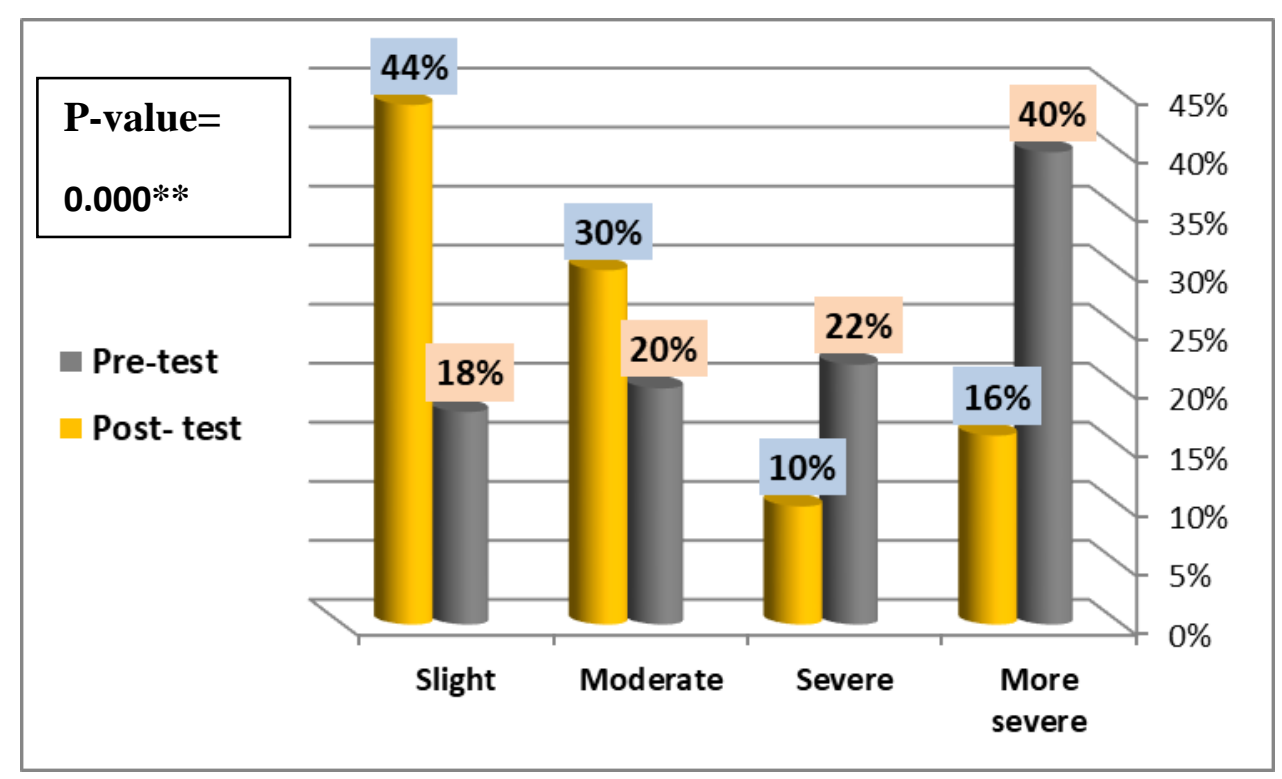

Figure (1): Comparison between the severity levels of stress urinary incontinence based on Revised urinary incontinence scale at Pre and Posttest among the studied sample $(\mathrm{N}=50)$.

Table (4): Comparison between the mean scores of Revised Urinary Incontinence Scale (RUIS) and Rosenberg Self-esteem Scale (RSES) before and after 12 weeks of behavioral training sessions for the participants $(\mathbf{N}=\mathbf{5 0})$.

\begin{tabular}{|l|c|c|c|c|}
\hline \multirow{2}{*}{ Variable } & Pre $(\mathrm{N}=50)$ & Post $(\mathrm{N}=50)$ & \multirow{2}{*}{ t-test } & \multirow{2}{*}{ P-value } \\
\cline { 2 - 3 } & Mean + SD & Mean + SD & & .001** \\
\hline RUIS & $\mathbf{8 . 2 0} \pm 5.21$ & $4.30 \pm 3.38$ & 10.1 & $0.000 * *$ \\
\hline RSES & $\mathbf{9 . 8 4} \pm 2.733$ & $15.48 \pm 5.75$ & 4.642 & $\mathbf{0 . 7 5}$ \\
\hline
\end{tabular}

$* p \leq 0.05$ (significant) 
Table (5): Correlation between the severity of stress urinary incontinence and self-esteem before and after 12 weeks of behavioral training sessions for the participants $(\mathrm{N}=50)$.

\begin{tabular}{|l|c|c|l|l|}
\hline \multirow{2}{*}{ Variable } & \multicolumn{4}{|c|}{ Severity of stress urinary incontinence } \\
\cline { 2 - 5 } & \multicolumn{3}{|c|}{ Pre } & \multicolumn{2}{c|}{ Post-test } \\
\cline { 2 - 5 } & $\mathbf{r}$ & P-Value & $\mathbf{r}$ & P-Value \\
\hline Self-esteem & $-.369-$ & $0.005^{* *}$ & $-.986-$ & $0.003^{* *}$ \\
\hline$* p \leq 0.05$ (significant) & \multicolumn{4}{|l}{} \\
\hline
\end{tabular}

Table (6): The correlation between the severity of stress urinary (SUI) and Personal characteristics of the studied sample at post-test $(\mathrm{N}=50)$.

\begin{tabular}{|l|c|c|}
\hline \multirow{2}{*}{ Variable } & \multicolumn{2}{c|}{ Severity of stress UI } \\
\cline { 2 - 3 } & r & P-value \\
\hline Age & .598 & $0.000^{* *}$ \\
\hline Education & $.388-$ & $0.003^{* *}$ \\
\hline Body Mass index & 0.635 & $0.001^{* *}$ \\
\hline Higher parity & .761 & $0.000^{* *}$ \\
\hline Chronic disease & .585 & $0.001^{* *}$ \\
\hline
\end{tabular}

$* p \leq 0.05$ (significant)

Table (1): Shows that (44\%) of the participants were in the age group of $(65<70)$ years old with a mean age of $(66.92 \pm 5.39)$. Also, the table displays that $(52 \%$, $58 \%$, and $72 \%$ ) were widows, have basic education, and with insufficient income respectively. Besides, $48 \%$ of them were obese and $68 \%$ had a positive family history of stress urinary incontinence.

Table (2): Illustrates that (86\%) of the elderly women have chronic diseases; the most reported chronic disorders were (hypertension, diabetes, arthritis, cardiovascular, and constipation. As regards obstetrical history, results revealed that vaginal deliveries took the highest percentage as a method of delivery and $58 \%$ of them had $\geq 4$ pregnancies times.

Table (3): Reveals that the duration of stress urinary incontinence was $\geq 5$ years among the vast majority of residents. Also, $84 \%$ of residents had more than one episode per day, and (44\% and $32 \%)$ of them reported a moderate and large amounts of SUI respectively. Likewise, $70 \%$ of the studied sample reported no action taken for managing this problem due to shame. Finally, it was found that (low selfesteem, poor hygiene, and limited social activities) were the most documented negative consequences among incontinent elderly women.

Figure (1): Displays the severity levels of stress UI based on the used Revised Urinary Incontinence Scale (RUIS) and reflects that the severity of SUI was declined after the application of the selective behavioral therapy to $16 \%$ compared to $40 \%$ before, with a highly statistically significant difference $(\mathrm{p}=.000)$. This table supported the research hypothesis.
Table (4): Illustrates that the mean score of urinary incontinence severity declined to $(4.30+3.38)$ among the studied sample after the application of behavioral training sessions compared to $(8.20+5.21)$ before, Consequently, the mean score of self-esteem was elevated to $(15.48 \pm 5.75)$ at posttest versus $(9.84 \pm 2.733)$ in before, with a highly statistical significant difference between pre and posttest $(\mathrm{p}=.000)$. This table achieved the research hypothesis. Table (5): Shows that there was a negative correlation between the severity of stress urinary incontinence and the level of self-esteem, in other words when the severity of SUI declined, the level of self-esteem elevated among the incontinent residents.

Table (6): Demonstrates that there were positive correlations between (age, body mass index, higher parity, and the presence of chronic disease), with the severity of stress urinary incontinence among the studied sample. While, there was a negative correlation between the education and stress urinary incontinence severity with a highly statistically significant difference.

\section{Discussion}

Stress urinary incontinence (SUI) is a prevalent health problem, especially in old age. Behavioral training therapy particularly (Kegel and bladder training exercises) became the first choice of its management, because of their effectiveness with low risks.

Hence this study was conducted to evaluate the effect of this selective behavioral therapy on the severity of stress urinary incontinence and self-esteem among institutionalized elderly women. 
The main findings of the current study had been discussed within the following frame of reference. Concerning demographic characteristics, results revealed that the mean age of the participants was $(68.92+5.39)$. In agreement with this finding, there were studies conducted in Egypt and Brazil by (Ali et al., 2020 \& Borges et al., 2019) revealed that more than half of the studied residential women who suffer from SUI were over 65yrs.

This can be discussed as the effects of the aging process on the bladder muscle tone and capacity, hormonal changes associated with menopause, and the presence of chronic diseases are interrelated factors that can increase the incidence of SUI among them.

The findings of the present study illustrated that the majority of the participants had a medical history of chronic diseases. This was in accordance with (Ali et al., 2020) who reflected a significant relationship between UI and comorbidities, particularly hypertension, diabetes, and chronic constipation. While another validation by (Kocaöz et al., 2015) stated that there was no significant between SUI and chronic disorders among residents of Turkish geriatric homes.

In this study, most incontinent residents reported moderate to large amounts of urinary losses several times per/day before the educational sessions and this reflected the magnetite of the problem. This was in agrees with (Roig et al., 2015) who found a higher frequency and amount of urinary loss among Brazilian elderly women in geriatric homes.

As regards adverse consequences of SUI, results demonstrated that low self-esteem, poor hygiene, and limited social activities) were the most documented negative consequences of SUI, and this was consistent with (Elserafya et al., 2020). This fact can be explained as elderly women with SUI often limit their involvement in social activities due to fears from odor, wetness, and discomfort, hence social withdrawal progresses and self-esteem declines

While the results of (Roig et al., 2015) reflected that dermatitis, itching, urinary tract infection, and bedsores were the commonest adverse effects of SUI reported by the studied sample, and this was against our findings.

The current study achieved our hypothesis in which after 12 weeks of compliance to selective behavioral training therapy included (Kegel exercise and bladder training) there was a significant decrease in the severity of SUI and a marked elevation in the level of self-esteem among the incontinent residents. This can be discussed as the Kegel exercise gradually increases the strength of pelvic floor muscles combined with bladder/toilet training which increases the capacity of urinary bladder; both are leading to that observed progress.

These findings were supported by the study conducted in Zagazig City-Egypt by (El Badawy et al., 2013) who observed a decrease in the amount and frequency of urinary leakage among the investigated group after the teaching program was implemented, compared to before. Furthermore, these findings confirmed those of (Karbage, et al., 2016 \& Marques et al., (2018), who mentioned that completing Kegel exercise on a regular basis strengthens the pelvic floor muscle and improves the control of SUI.

Similarly, the previous studies conducted in Egypt and Australia by (Elbana et al., 2018 \& Gümüşsoy et al., 2019 respectively) supported our findings in which they demonstrated that SUI severity influences adversely on self-esteem and the body image of incontinent women with a significant negative correlation between stressUI and self-esteem was discovered.

On other hand, these findings was against (Tran et al., 2013), who reported a little improvement in UI symptoms among the experimental group and discussed that this type of behavioral therapy need a high level of compliance and motivation to be an effective. Also, it was diversely (Marques et al., 2018) who stated poor effect of the behavioral intervention can trigger by morbid obesity, comorbidities, and higher parity.

Furthermore, the results of the current study showed elderly women above the age of seventy years showed less improvement in SUI symptoms as well as those of overweight and higher parity than others. This is matching with (Aylaz et al., 2016) who stated a greater deterioration for the strength of pelvis structures associated with advanced age and obesity.

Also, another validation by (Pourmomeny et al., 2018) reflected that multipara and obesity affect negatively of the severity of SUI and this is in the same line with our findings. Diversely, the research that is applicated in Menoufia by (Elserafya et al., 2020) reflected no significant relationship was observed between various UI types and obstetrical history.

Concerning the educational level, a negative correlation was detected between education and SUI severity, which was consistent with (Fouad \& Hafez 2017 \& Abdel Aziz et al., 2019), who stated that educated elderly participants had fewer episodes of incontinence than non-educated at posttest and discussed that education is an important factor in recognizing educational instructions and compliance level to behavioral therapy. 
Study limitations:

- There was 6 participants decided to withdraw and cannot adhere to the behavioral therapy for 12 weeks, so researchers replaced them with another six participants.

- The personal face-to-face interview during this study induced feelings of shame and embarrassment for some participants to report their experiences of stress UI openly.

- The sample size was small which limiting the generalization of the findings.

\section{Conclusion:}

Based on the findings of this study, it can be stated that using selected behavioral training therapy (Kegel and toilet training exercises) was effective in reducing the severity of SUI and, as a result, elevating selfesteem among institutionalized elderly women.

\section{Recommendations:}

- Behavioral training sessions are recommended to be offered regularly for geriatric residents to improve their self-esteem by controlling stress urinary incontinence.

- Planning an educational intervention for nurses at geriatric homes regarding risk factors of urinary incontinence and non-pharmacological methods of its management.

- Comparison between behavioral techniques and other methods of treatment to control urinary loss among incontinent elders.

- Replication of the current study on a larger probability sample and other health care settings.

\section{References}

- Abdel-Aziz, N., Ibrahim S., \& Abdelkader A., (2019): Effect of Kegel's Exercise on Severity of Urinary Incontinence and Quality of Life among Menopausal Women. International Journal of Novel Research in Healthcare and Nursing Vol. 6, Issue 3, pp: (1288-1308).

- Aly W., Sweed H., Mossad N., \& Tolba M. (2020): Prevalence and Risk Factors of Urinary Incontinence in Frail Elderly Females. Journal of Aging Research Volume 2020, Article ID 2425945, 8 pages.

- Aylaz R., Işık K., Bayır B., \& Yetiş G. (2016): The effect of urinary incontinence on quality of life in women 65 years and older. İnönü Üniversitesi Sağlık Bilimleri Dergisi, 5(2), 19-25.

- Borges CL, Fernandes BC, Cavalcante MN, Barbosa RG, \& Menezes LC. (2019): Risk factors for urinary incontinence in institutionalized elderly. ESTIMA, Braz. J. Enterostomal Ther., 16: e0619.
- El Badawy R., Ali S., Abo El-Seoud A., \& Abd Allah E. (2013): Health Education Intervention for Controlling of Stress Urinary Incontinence among Elderly Women at Zagazig City. Zagazig Nursing Journal, 9(2), 49-65.

- Elbana H., Salama A., \& Barakat M. (2018): Effect of Urinary Incontinence on Quality of Life and Self Esteem of Postmenopausal Women. American Journal of Nursing Science 2018; 7(5): 182-191.

- Elserafya F., Shaheenb H., \& Khalil N., (2020): Urinary incontinence among elderly women attending a rural family health center in Gharbiya Governorate. Menoufia Medical Journal, Volume 32- Number 3PP 955-960.

- Fouad R. \& Hafez S. (2017): Impact of Urinary Incontinence on Self Esteem and Quality of Life of Elderly Females Residing in Assisted Living Facilities. ASNJ; 19(1): 91-108.

- Gümüşsoy S., Kavlak O., \& Dönmez S., (2019): Investigation of body image, self-esteem, and quality of life in women with urinary incontinence. Int J Nurs Pract.; 25: e12762.

- https://www.surveysystem.com/sscalc.htm (2019). Sample size Calculator-Confidence level, Confidence Interval, Sample size, Relevant population-Creative research Systems.

- International Continence Society (ICS) (2018): Joint Report on the Terminology for Female Pelvic Floor Dysfunction.

- Ismail N., Ibrahim H., \& Rady S., (2019): Effect of Kegel Exercise on Severity of Urinary Incontinence and Quality of Life among Menopausal Women. International Journal of Novel Research in Healthcare and Nursing Vol. 6, Issue 3, pp: (1288-1308).

- Jahromi M., Talebizadeh M., \& Mirzaei M., (2015): The Effect of Pelvic Muscle Exercises on Urinary Incontinency of Elderly Females With Stress Urinary Incontinency. Global Journal of Health Science; Vol. 7, No. 2:71-79.

- Karbage S., Santos Z., Frota M., Moura, H., Vasconcelos C., Neto J., \& Bezerra L. (2016): Quality of life of Brazilian women with urinary incontinence and the impact on their self-esteem. European Journal of Obstetrics, Gynecology, and Reproductive Biology, 201, 56-60.

- Kocaöz S, Bilgili N., \& Eroglu K. (2015): Prevalence and risk factors of urinary incontinence in Turkish Nursing Homes: A cross-sectional study. Pak J Med Sci; 25 (1):18-25.

- Kramer M., Logan S., \& Yong E. (2020): Risk factors and prevalence of urinary incontinence in mid-life Singaporean women: the integrated Women's health program. International urogynecology journal, 31(9), 1829-1837. 
- Marques A., Lynn S., \& Andrew M. (2018): The status of pelvic floor muscle training for women. Can Urol Assoc J; 4(6): 419-424.

- Mohammed, H., Hafez, S., \& Basyouni, N. (2018): Effect of Pelvic Floor Muscle Strengthening-Kegel's Exercise-on Severity of Stress Urinary Incontinence and Quality of Life among Women. International Journal of Novel Research in Healthcare and Nursing Vol. 5, Issue 3, pp: (421-438).

- Mulvey MA., Schilling JD., Martinez JJ., \& Hultgren SJ. (2017): Bad bugs and beleaguered bladders: interplay between uropathogenic Escherichia coli and innate host defenses. Proceedings of the National Academy of Sciences of the United States of America. Aug 1; 97(16):8829-8835.

- Palmer MH. (2015): Effectiveness of prompted voiding for incontinent nursing home residents. In: Mazurek-Melnyk B, Fineout-Overholt E, editors. Evidence-Based Practice in Nursing and Healthcare: A Guide to the Best Practice. Philadelphia: Lippincott Williams \& Wilkins;. pp. CD20-CD30.

- Pourmomeny A., Torkzadeh A., \& Zargham M (2018): Effects of Special Pelvic Floor Muscle Training on the Quality of Life in Women with Urinary Incontinence, A Clinical Trial. Journal of Rehabilitation Sciences and Research;5:106-110.

- Roig J., Bezerra D., \& Lima K., (2015):Urinary incontinence in institutionalized elderly: prevalence and impact on quality of life Fisioter Mov. 2015 July/Sept; 28(3):583-96.

- Rosenberg M., (1965): Society and the adolescent self-image. Princeton, NJ: Princeton University Press. online pdf: https://www.docdroid.net/Vt9xpBg/societyand-the-adolescent-self-image-morris-rosenberg1965.

- Sandvic H., Seim A.,Vanivik A., \& Hunskaar S.(2000): A severity index for epidemiological survays of female urinary incontinence: comparison with 48-hour tests. Neurouorology and urodynamics [Internet]. 19;137: 45

- Shaw C. \& Wagg A. (2017): Urinary incontinence in older adults. Medicine, vol. 45, no. 1, pp. 23-27.

- Simpson N., Garbens A., Dossa F., Coyte P., Baxter N., \& McDermott D. (2019): A cost-utility analysis of nonsurgical treatments for stress urinary incontinence in women. Female pelvic medicine \& reconstructive surgery, 25(1), 49-55.

- Tran K, Levin RM, \& Mousa SA (2013): Behavioral intervention versus Pharmacotherapy or their combinations in the management of urinary incontinence among elderly women. J Am Geriatr Soc 38: 282-288.
- Vaz, C., Sampaio, R., Saltiel, F., \& Figueiredo, E. (2019): Effectiveness of pelvic floor muscle training and bladder training for women with urinary incontinence in primary care: a pragmatic controlled trial. Brazilian journal of physical therapy, 23(2), 116-124.

- World Health Organization (2006): BMI classification". Global database on body mass index.

.http://apps.who.int/bmi/index.jsp?introPage=intro 3.html. 